\title{
RESEARCH
}

Open Access

\section{Different surgical outcome and follow-up status between dMMR and pMMR colorectal cancer patients who fulfilled with Amsterdam-II criteria}

Ci-Yuan Sun ${ }^{1,2^{*+}}$ D, Jy-Ming Chiang ${ }^{1,3+}$, Tse-Ching Chen ${ }^{3,4}$, Hsin-Yun Hung ${ }^{1}$ and Jeng-Fu You ${ }^{1}$

\begin{abstract}
Background: Although hereditary non-polyposis colorectal cancer (HNPCC) could be subtyped into proficient or deficient mismatch repair gene expression (pMMR or dMMR), distinct clinical features between these two subgroups patients were rarely reported.

Methods: We retrospectively analyzed 175 hereditary non-polyposis colorectal cancer (HNPCC) patients between January 1995 and December 2012. Cox proportional hazards model was used to compare the differences between two subgroups.

Results: Significant differences of disease free survival (DFS) and overall survival (OS) exist between dMMR and pMMR. In addition to other factors including younger mean age of diagnosis for dMMR patients (48.6 years vs. 54.3 years), operation type (more extended colectomy for dMMR 35.8\% vs. 14.5\%), tumor location (right colon predominance for dMMR $61.7 \%$ vs. $27.3 \%$ and more rectum cases for pMMR $41.8 \%$ vs. $11.7 \%$ ), tumor differentiation (more poor differentiation for dMMR 23.3\% vs. 9.0\%), N staging (more N0 cases for dMMR 70.8\% vs. 50.9\%), more frequently presence of extra-colonic tumors for dMMR (16.7\% vs.1.8\%), and lower recurrence rates (9.1\% vs.35.3\%). Significantly different cumulative incidences of developing metachronous colorectal cancer were observed with 6.18 for pMMR patients and 20.57 person-years for dMMR patients $(p<0.001)$.

Conclusions: Distinct clinicopathological features significantly exist between dMMR and pMMR subtypes patient, MMR status should be consider to tailor operation types and follow up surveillance between these two subgroups patients who all fulfilled with Amsterdam-Il criteria.
\end{abstract}

Keywords: Mismatch repair gene expression, Hereditary non-polyposis colorectal cancer, Metachronous colon tumor, Extra-colonic tumors

\footnotetext{
* Correspondence: iota623@cgmh.org.tw

${ }^{+}$Ci-Yuan Sun and Jy-Ming Chiang contributed equally to this work.

'Division of Colon and Rectal Surgery, Department of Surgery, Chang Gung Memorial Hospital, Lin-Kou Medical Center, Tao-Yuan, Taiwan

${ }^{2}$ College of Medicine, Chang Gung University, No. 5, Fu-Hsing Rd. Kuei-Shan, Tao-Yuan 333, Taiwan

Full list of author information is available at the end of the article
}

(c) The Author(s). 2020 Open Access This article is licensed under a Creative Commons Attribution 4.0 International License, which permits use, sharing, adaptation, distribution and reproduction in any medium or format, as long as you give appropriate credit to the original author(s) and the source, provide a link to the Creative Commons licence, and indicate if changes were made. The images or other third party material in this article are included in the article's Creative Commons licence, unless indicated otherwise in a credit line to the material. If material is not included in the article's Creative Commons licence and your intended use is not permitted by statutory regulation or exceeds the permitted use, you will need to obtain permission directly from the copyright holder. To view a copy of this licence, visit http://creativecommons.org/licenses/by/4.0/. The Creative Commons Public Domain Dedication waiver (http://creativecommons.org/publicdomain/zero/1.0/) applies to the data made available in this article, unless otherwise stated in a credit line to the data. 


\section{Background}

Patients with hereditary non-polyposis colorectal cancer (HNPCC) may be stratified into Lynch syndrome (LS) and familial colorectal cancer type X (FCCTX) based on the immunohistochemical staining of mismatch repair (MMR) protein expression or microsatellite instability analysis [1]. Patients with deficient mismatch repair gene expression (dMMR) or LS are reported to have certain clinicopathological characteristics including a higher risk of metachronous colorectal tumors [2], younger age at onset, right-side colon predominance, higher proportion of poorly differentiated tumors, mucinous adenocarcinoma [2-5], and a specific tumor lymphocyte infiltration pattern [3]. These histopathologic characteristics may not be shared by patients with proficient mismatch repair gene expression (pMMR) or familial colorectal cancer type X $[1,6]$. In addition, patients with FCCTX do not have an increased risk of extra-colonic cancers [6]. Different clinical features were reported. However, differences in surgical outcomes and operation types between these two subgroups of patients have rarely been reported.

For patients with dMMR or Lynch syndrome, extended colectomy such as subtotal or total colectomy, rather than hemicolectomy or segmental resection, is recommended due to the increased risk of metachronous colorectal cancer (CRC) $[7,8]$. Performing the recommended surgical intervention has been shown to significantly decrease the rate of metachronous colorectal lesions [2, 9-11]; however, the survival rate did not significantly improve for the extended colectomy subgroups. These patients might die from secondary tumors; we questioned whether extended colectomy was necessary for all HNPCC patients with dMMR as well. In this retrospective study, we analyzed 175 patients with HNPCC, including 120 with dMMR and 55 with pMMR, to investigate whether there are differences in surgical outcomes and post-operation follow-up status between dMMR and pMMR subgroups.

\section{Methods}

\section{Patients and methods}

Between January 1995 and December 2012, 14479 patients underwent colectomy for CRC and were recorded in the CRC Registry of Chang Gung Memorial Hospital. Of these, 175 patients who fulfilled the Amsterdam-II criteria (A-II C) were retrieved. The CRC revised computerized registry was established in 1995 in Chang Gung Memorial Hospital. This database includes records of detailed family histories, demographic variables, preoperative evaluation, surgery, and postoperative followup [12]. Patients fulfilling the A-II C (at least three relatives with a Lynch-associated cancer, one being a first-degree relative of the other two; at least two successive generations affected; and at least one person diagnosed before 50 years of age) were defined as having HNPCC.

We adopted neoadjuvant radiotherapy or chemoradiation for high-risk rectal cancer and low rectal cancer. This decreased the local recurrence rate but had no significant effect on distant metastases. Postoperative adjuvant chemotherapy was adopted for all stage III colon cancers and high-risk stage II colon cancers. Postoperative follow-up surveillance included colonoscopy 1 year after colectomy, and then every 1 to 3 years determined on an individual basis according to the status of previous colonoscopic findings. Annual CT for the first three postoperative years was recommended by the NCCN and ESMO guidelines. Some surgeons strictly followed this approach as part of regular follow-up. However, in our hospital, a modified CEA follow-up protocol was adopted in our study. CEA level was measured every $3 \sim 4$ months in the first 2 years after the operation and every 6 months thereafter in the following 3 years. We performed abdominal CT for patients with elevated CEA level during follow-up since elevation in CEA level may precede clinical symptoms of recurrence for colorectal cancer patients. We also performed CT for patients with abnormal physical examination, such as palpable abdominal mass. Follow-up data were added annually by reviewing patients' records in medical charts. A telephone interview or mail questionnaire was conducted if a patient's medical records were not available. The study was approved by the IRB of Chang Gung Memorial Hospital (IRB102-2284B).

\section{IHC analysis for MMR protein expression}

Paraffin-embedded tumor blocks from HNPCC patients were retrieved from the Pathology Department of Chang Gung Memorial Hospital. For each patient, 4- $\mu$ m-thick sections from one formalin-fixed, paraffin-embedded tissue block containing both tumor tissue and normal adjacent mucosa were obtained. Immunostaining was performed using a Dako Universal Autostainer (DakoCytomation, Denmark) by using ChemMateTM EnvisonTM + Detection kits (DakoCytomation, Denmark) as previously described [12].

\section{Assessment of MMR protein expression}

For the evaluation of IHC results, abnormal staining was defined as total loss of protein in the tumor, using appropriate controls; staining was considered assessable when the nucleus was stained in cells serving as internal controls, including either stromal or germinal follicle lymphocytes or normal epithelial cells in the crypt bases. Tumors were considered negative for MMR protein expression when neoplastic cells showed complete absence of detectable nuclear staining in a sample for which 
Table 1 Clinicopathological characteristics of HNPCC patients, and comparisons of between $\mathrm{dMMR}$ and PMMR patients

\begin{tabular}{|c|c|c|c|c|c|c|c|c|c|}
\hline \multirow[t]{3}{*}{ Characteristics } & \multirow{3}{*}{$\begin{array}{l}\text { All patients } \\
(N=175)\end{array}$} & \multicolumn{2}{|l|}{ HNPCC } & \multirow[t]{3}{*}{$p$ value } & \multicolumn{5}{|l|}{ (Continued) } \\
\hline & & \multirow{2}{*}{$\begin{array}{l}\text { pMMR } \\
(n=55)\end{array}$} & \multirow{2}{*}{$\begin{array}{l}\text { dMMR } \\
(n=120)\end{array}$} & & \multirow[t]{3}{*}{ Characteristics } & \multirow{3}{*}{$\begin{array}{l}\text { All patients } \\
(N=175)\end{array}$} & \multicolumn{2}{|l|}{ HNPCC } & \multirow[t]{3}{*}{$p$ value } \\
\hline & & & & & & & \multirow{2}{*}{$\begin{array}{l}\text { pMMR } \\
(n=55)\end{array}$} & \multirow{2}{*}{$\begin{array}{l}\text { dMMR } \\
(n=120)\end{array}$} & \\
\hline Age & & & & & & & & & \\
\hline Mean (SD) & $50.41(12.98)$ & $54.31(13.66)$ & $48.62(12.30)$ & 0.007 & Present & $29(16.57)$ & $1(1.82)$ & $10(8.33)$ & \\
\hline Median (range) & $49(26 \sim 88)$ & 51 (29 88) & $48(26 \sim 78)$ & 0.017 & Death & & & & 0.003 \\
\hline Sex & & & & 0.054 & Alive & $128(73.14)$ & $32(58.18)$ & $96(80.00)$ & \\
\hline $\mathrm{F}$ & $92(52.57)$ & $23(41.82)$ & $69(57.50)$ & & Deceased & $47(26.86)$ & $23(41.82)$ & $24(20.00)$ & \\
\hline M & $83(47.43)$ & $32(58.18)$ & $51(42.50)$ & & Follow-up month & $\begin{array}{l}97.08 \\
(0.00 \sim 239.93)\end{array}$ & $\begin{array}{l}69.78 \\
(0.00 \sim 137.95)\end{array}$ & $\begin{array}{l}117.47 \\
(0.00 \sim 239.93)\end{array}$ & 0.014 \\
\hline
\end{tabular}

colectomy

Extended

colectomy

Tumor location

Right colon

89 (50.86)

47 (85.45)

77 (64.17)

51 (29.14)

$8(14.55)$

43 (35.83)

Left colon

49 (28.00)

15 (27.27)

74 (61.67)

Rectum

37 (21.14)

17 (30.91)

32 (26.67)

Tumor histology

Adenocarcinoma

Mucinous/signet

ring

Unclassified $\quad 4(2.29)$

Tumor differentiation

Well

30 (17.14)

$23(41.82)$

14 (11.67)

146 (83.43)

49 (89.09)

97 (80.83)

25 (14.29)

5 (9.09)

20 (16.67)

1 (1.82)

$3(2.50)$

12 (21.82)

18 (15.00)

Moderate

Poor

Unclassified

109 (62.29)

38 (69.09)

71 (59.17)

28 (23.33)

3 (2.50)

TNM_T stage

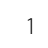

2

3

4

TNM_N stage

0

1

2

3

TNM_M stage

0

1

Disease recurrence

No

3 (1.71)

$0(0.00)$

$13(7.51)$

5 (9.43)

3 (5.66)

$85(49.13)$

$30(56.60)$

61 (35.26)

15 (28.30)

$8(6.67)$

11 (9.17)

55 (45.83)

46 (38.33)

112 (64.74)

27 (50.94)

85 (70.83)

37 (21.39)

15 (28.30)

22 (18.33)

20 (11.56)

10 (18.87)

10 (8.33)

$3(2.50)$

161 (92.00)

51 (92.73)

$110(91.67)$

$10(8.33)$

$<0.001$

100 (90.90)

Yes

133 (76.00)

33 (64.70)

10 (9.10)

Extra-colonic tumor

Absent

42 (24.00)

18 (35.30)

$100(83.33)$

Present

154 (88.00)

54 (98.18)

20 (16.67)

Metachronous colon tumor

Absent

$146(83.43)$

$54(98.18)$
Table 1 Clinicopathological characteristics of HNPCC patients, and comparisons of between $\mathrm{dMMR}$ and pMMR patients (Continued)

internal positive controls were stained. A pathologist who had no knowledge of the family history or other clinicopathological features, reviewed all cases to confirm the immunostaining results.

\section{Statistical analyses}

Pearson's chi-square, Fisher's exact, and the Wilcoxon rank-sum tests were used to evaluate the distribution of patient characteristics between patients with LS and FCCTX. Survival curves were estimated using the Kaplan-Meier method. In univariate survival analysis, the associations between patient characteristics and disease-free survival (DFS) and overall survival (OS) were evaluated using the log-rank test. The Cox proportional hazards model was used to investigate the effect of patient characteristics on survival while adjusting for other explanatory variables. The rate of metachronous CRC was calculated as the number of secondary cancers divided by the number of observed person-years during the follow-up period. In order to explore the association between patient subgroups and risk of secondary cancer occurrence, the risk ratio of the cumulative incidence of secondary malignancies was also estimated using the Cox proportional hazards model. All statistical analyses were performed using SPSS 17 software (SPSS, Inc., Chicago, IL). The $p$ values were two-sided and those $<0.05$ were considered statistically significant.

\section{Results}

Overall, 68.6\% (120/175) of the HNPCC patients demonstrated loss of at least one MMR protein. The distribution of the loss of MMR protein expression included concordant losses of MLH1/PMS2 staining (83 patients, 69.2\%), MSH2/MSH6 staining (33 patients, 27.5\%), and loss of PMS2 only (4 patients, 3.3\%). As shown in Table 1, there were several significant differences between dMMR and pMMR patients in terms of clinical and histopathological characteristics: mean age of diagnosis (younger for dMMR patients 48.6 vs. 54.3 years), operation type (more extended colectomy for dMMR $35.8 \%$ vs. $14.5 \%$ ), tumor location (right colon predominance for dMMR 61.7\% vs. 
$27.3 \%$, and more rectum cases for pMMR $41.8 \%$ vs. 11.7\%), tumor differentiation (more poor differentiation for dMMR $23.3 \%$ vs. 9.0\%), $\mathrm{N}$ stage (more N0 cases for dMMR $70.8 \%$ vs. $50.9 \%$ ), presence of extra-colonic tumors (more frequent for dMMR 16.7\% vs.1.8\%), and recurrence rate (lower for dMMR 9.1\% vs. 35.3\%). Although the crude rate of metachronous $\mathrm{CRC}$ was not significantly different $(8.3 \%$ vs. $1.8 \%, p=0.177)$, the cumulative incidence of

Table 2 Factors related to operation types

\begin{tabular}{|c|c|c|c|c|}
\hline \multirow[t]{2}{*}{ Characteristics } & \multirow{2}{*}{$\begin{array}{l}\text { All patients } \\
n(\%)\end{array}$} & \multicolumn{2}{|l|}{ Operation type } & \multirow{2}{*}{$\begin{array}{l}p \\
\text { value }\end{array}$} \\
\hline & & Hemicolectomy & Sub/total colectomy & \\
\hline HNPCC & & & & 0.004 \\
\hline pMMR & $55(31.43)$ & $47(85.45)$ & $8(14.55)$ & \\
\hline $\mathrm{dMMR}$ & $120(68.57)$ & $77(64.17)$ & $43(35.83)$ & \\
\hline Age & & & & - \\
\hline Mean (SD) & $50.41(12.98)$ & $51.77(13.77)$ & $47.10(10.21)$ & \\
\hline Median (range) & $49(26-88)$ & $49(26-88)$ & $48(29-75)$ & \\
\hline Sex & & & & 0.466 \\
\hline $\mathrm{F}$ & $92(52.57)$ & $63(68.48)$ & $29(31.52)$ & \\
\hline M & $83(47.43)$ & $61(73.49)$ & $22(26.51)$ & \\
\hline Tumor location & & & & 0.005 \\
\hline Right colon & $89(50.86)$ & $60(67.42)$ & $29(32.58)$ & \\
\hline Left colon & $49(28.00)$ & $30(61.22)$ & $19(38.78)$ & \\
\hline Rectum & $37(21.14)$ & $34(91.89)$ & $3(8.11)$ & \\
\hline Tumor histology & & & & 0.212 \\
\hline Adenocarcinoma & $146(83.43)$ & $107(73.29)$ & $39(26.71)$ & \\
\hline Mucinous/signet ring & $25(14.29)$ & $15(60.00)$ & $10(40.00)$ & \\
\hline Unclassified & $4(2.29)$ & $2(50.00)$ & $2(50.00)$ & \\
\hline Tumor differentiation & & & & 0.265 \\
\hline Well & $30(17.14)$ & $22(74.31)$ & $8(26.67)$ & \\
\hline Moderate & $109(62.29)$ & $81(74.31)$ & $28(25.69)$ & \\
\hline Poor & 33 (18.86) & $19(57.58)$ & $14(42.42)$ & \\
\hline Unclassified & $3(1.71)$ & $2(66.67)$ & $1(33.33)$ & \\
\hline TNM_T stage & & & & 0.367 \\
\hline 1 & $13(7.51)$ & $9(69.23)$ & $4(30.77)$ & \\
\hline 2 & 14 (8.09) & $9(64.29)$ & $5(35.71)$ & \\
\hline 3 & $85(49.13)$ & $65(76.47)$ & $20(23.53)$ & \\
\hline 4 & $61(35.26)$ & $39(63.93)$ & $22(36.07)$ & \\
\hline TNM_N stage & & & & 0.403 \\
\hline 0 & $112(64.74)$ & $75(66.96)$ & $37(35.04)$ & \\
\hline 1 & 37 (21.39) & 27 (72.97) & $10(27.03)$ & \\
\hline 2 & $20(11.56)$ & $17(85.00)$ & $3(15.00)$ & \\
\hline 3 & $4(2.31)$ & $3(75.00)$ & $1(25.00)$ & \\
\hline TNM_M stage & & & & 0.069 \\
\hline 0 & 161 (92.00) & $111(68.94)$ & $50(31.06)$ & \\
\hline 1 & $14(8.00)$ & $13(92.86)$ & $1(7.14)$ & \\
\hline TNM staging & & & & 0.143 \\
\hline |/II & $111(63.43)$ & $75(67.57)$ & $36(32.43)$ & \\
\hline III & $50(28.57)$ & $36(72.00)$ & $14(28.00)$ & \\
\hline IV & $14(8.00)$ & $13(92.86)$ & $1(7.14)$ & \\
\hline
\end{tabular}


developing metachronous CRC was different (6.18 for pMMR patients and 20.57 person-years for dMMR patients; $p<0.001$ ).

The operation type (extended colectomy vs. segmental colectomy) was significantly associated with the subtype of HNPCC and tumor location. Patients who underwent segmental colectomy were more likely to have tumors in the rectum compared to those who underwent extended colectomy $(34 / 37,91.9 \%$ vs. $3 / 37,8.1 \% ; p=0.005)$ (Table 2$)$ compared to tumors located in the right or left colon. In addition, the rate of extended colectomy was significantly different between dMMR and pMMR patients $(35.8 \%$ vs. $14.5 \%, p=0.004)$ (Table 2).
In this study, the average follow-up duration for all patients was 97.1 months and was 69.8 and 117.5 months for pMMR and dMMR patients, respectively. DFS and OS were compared between dMMR and pMMR patients in terms of different clinicopathological variables. Univariate analysis revealed significant differences in DFS based on subtype of HNPCC (dMMR vs. pMMR), type of operation (extended or segmental colectomy), tumor location (right colon, left colon, or rectum), and presence of lymph node metastases ( $\mathrm{N}$ staging) (Table 3). Multivariate analysis confirmed the significant differences in DFS for subtype of HNPCC (dMMR better than pMMR) and N

Table 3 Univariate and multivariate analyses of disease-free survival (DFS) related to clinical variables

\begin{tabular}{|c|c|c|c|c|c|c|c|c|}
\hline \multirow[t]{2}{*}{ Characteristics } & \multirow[t]{2}{*}{$N$} & \multicolumn{3}{|l|}{ DFS (\%) } & \multirow[t]{2}{*}{$p$ value } & \multicolumn{3}{|c|}{ Multiple Cox } \\
\hline & & 1 year & 3 years & 5 years & & $\mathrm{HR}$ & 95\% C.I. & $p$ \\
\hline HNHPCC & & & & & $<0.001$ & & & \\
\hline pMMR & 51 & 84.00 & 67.94 & 63.40 & & 1 & & \\
\hline $\mathrm{dMMR}$ & 110 & 96.25 & 94.37 & 93.42 & & 0.28 & $(0.108 \sim 0.733)$ & 0.009 \\
\hline Sex & & & & & 0.147 & & & \\
\hline F & 86 & 95.18 & 89.14 & 86.65 & & & & \\
\hline M & 75 & 89.13 & 82.27 & 0.00 & & & & \\
\hline Operation type & & & & & 0.029 & & & \\
\hline Hemicolectomy & 111 & 88.75 & 80.24 & 78.27 & & 1 & & \\
\hline Sub/total colectomy & 50 & 100.00 & 98.00 & 96.00 & & 0.41 & $(0.113 \sim 1.523)$ & 0.185 \\
\hline Tumor location & & & & & $<0.001$ & & & \\
\hline Right colon & 82 & 97.48 & 93.67 & 93.67 & & 1 & & \\
\hline Left colon & 48 & 89.58 & 85.42 & 81.14 & & 1.93 & $(0.601 \sim 6.212)$ & 0.269 \\
\hline Rectum & 31 & 82.76 & 65.52 & 62.07 & & 1.97 & $(0.581 \sim 6.663)$ & 0.276 \\
\hline Tumor histology & & & & & 0.522 & & & \\
\hline Adenocarcinoma & 134 & 92.34 & 85.41 & 83.03 & & & & \\
\hline Mucinous/signet ring & 23 & 95.45 & 90.91 & 90.91 & & & & \\
\hline Unclassified & 4 & 75.00 & 75.00 & 75.00 & & & & \\
\hline Tumor differentiation & & & & & 0.360 & & & \\
\hline Well & 29 & 100.00 & 96.55 & 92.69 & & & & \\
\hline Moderate & 100 & 89.75 & 82.52 & 80.41 & & & & \\
\hline Poor & 29 & 92.86 & 85.71 & 85.71 & & & & \\
\hline TNM_T stage & & & & & 0.678 & & & \\
\hline 1 & 13 & 100.00 & 92.31 & 92.31 & & 1 & & \\
\hline 2 & 14 & 92.86 & 92.86 & 92.86 & & 0.58 & $(0.052 \sim 6.567)$ & 0.662 \\
\hline 3 & 82 & 91.22 & 83.61 & 79.67 & & 0.75 & $(0.147 \sim 3.786)$ & 0.724 \\
\hline 4 & 52 & 92.00 & 86.00 & 86.00 & & 0.86 & $(0.154 \sim 4.773)$ & 0.861 \\
\hline TNM_N stage & & & & & $<0.001$ & & & \\
\hline 0 & 111 & 98.13 & 92.52 & 91.54 & & 1 & & \\
\hline 1 & 33 & 93.84 & 90.61 & 87.25 & & 1.10 & $(0.314 \sim 3.873)$ & 0.879 \\
\hline 2 & 16 & 50.00 & 37.50 & 31.25 & & 11.22 & $(4.015 \sim 31.343)$ & $<0.001$ \\
\hline 3 & 1 & 100.00 & - & - & & 125.71 & (9.975 1584.441) & $<0.001$ \\
\hline
\end{tabular}


staging ( $\mathrm{N} 2 / 3$ worse than N0) (Table 3). Univariate analysis revealed significant differences in OS based on HNPCC subtype (dMMR and pMMR), type of colectomy, tumor location, and $\mathrm{N}$ staging (Table 4); however, in multivariate analysis, a significantly better OS was only found between HNPCC types (dMMR better than pMMR) and $\mathrm{N}$ staging (N2/n3 worse than N0) after adjusting for confounding factors.

\section{Discussion}

In this study, we found significantly better DFS and OS for dMMR subtype patients compared with pMMR subtype patients, although both were classified clinically as HNPCC. Furthermore, similar to LS and FCCTX have different phenotypic features, we found significant differences existing between dMMR and pMMR subtype patients, as summarized in Table 5, a review of the

Table 4 Univariate and multivariate analyses of overall survival (OS) related to clinical variables

\begin{tabular}{|c|c|c|c|c|c|c|c|c|}
\hline \multirow[t]{2}{*}{ Characteristics } & \multirow[t]{2}{*}{$N$} & \multicolumn{3}{|l|}{ OS (\%) } & \multirow[t]{2}{*}{$p$ value } & \multicolumn{3}{|c|}{ Multiple Cox } \\
\hline & & 1 years & 3 years & 5 years & & $\mathrm{HR}$ & 95\% C.I. & $p$ \\
\hline NHPCC & & & & & $<0.001$ & & & \\
\hline pMMR & 55 & 92.59 & 74.07 & 64.51 & & 1 & & \\
\hline $\mathrm{dMMR}$ & 120 & 94.95 & 88.97 & 87.25 & & 0.48 & $(0.239 \sim 0.966)$ & 0.040 \\
\hline Sex & & & & & 0.548 & & & \\
\hline $\mathrm{F}$ & 92 & 94.57 & 85.78 & 81.38 & & & & \\
\hline M & 83 & 93.81 & 82.55 & 78.7 & & & & \\
\hline Operation type & & & & & 0.006 & & & \\
\hline Hemicolectomy & 124 & 91.8 & 78.45 & 73.4 & & 1 & & \\
\hline Sub/total colectomy & 51 & 100 & 98.04 & 96.04 & & 0.57 & $(0.242 \sim 1.348)$ & 0.201 \\
\hline Tumor location & & & & & $<0.001$ & & & \\
\hline Right colon & 89 & 94.25 & 88.36 & 86.01 & & 1 & & \\
\hline Left colon & 49 & 97.96 & 91.84 & 89.8 & & 1.25 & $(0.568 \sim 2.731)$ & 0.584 \\
\hline Rectum & 37 & 89.19 & 64.86 & 53.51 & & 1.42 & $(0.629 \sim 3.217)$ & 0.397 \\
\hline Tumor histology & & & & & 0.281 & & & \\
\hline Adenocarcinoma & 146 & 95.17 & 83.98 & 79.04 & & & & \\
\hline Mucinous/signet ring & 25 & 91.67 & 87.5 & 87.5 & & & & \\
\hline Unclassified & 4 & 75 & 75 & 75 & & & & \\
\hline Tumor differentiation & & & & & 0.276 & & & \\
\hline Well & 30 & 100 & 100 & 92.98 & & & & \\
\hline Moderate & 109 & 93.57 & 81.53 & 76.89 & & & & \\
\hline Poor & 33 & 90.63 & 80.92 & 80.92 & & & & \\
\hline Unclassified & 3 & 100 & 66.67 & 66.67 & & & & \\
\hline TNM_T stage & & & & & 0.255 & & & \\
\hline 1 & 13 & 100 & 100 & 83.92 & & & & \\
\hline 2 & 14 & 92.86 & 92.86 & 92.86 & & & & \\
\hline 3 & 85 & 98.81 & 84.17 & 81.69 & & & & \\
\hline 4 & 61 & 88.52 & 80.33 & 75.41 & & & & \\
\hline TNM_N stage & & & & & $<0.001$ & & & \\
\hline 0 & 112 & 97.3 & 92.79 & 89.16 & & 1 & & \\
\hline 1 & 37 & 97.3 & 88.71 & 82.78 & & 1.18 & $(0.504 \sim 2.757)$ & 0.704 \\
\hline 2 & 20 & 85 & 50 & 45 & & 4.70 & $(2.063 \sim 10.713)$ & $<0.001$ \\
\hline 3 & 4 & 50 & - & - & & 7.41 & $(1.563 \sim 35.110)$ & 0.012 \\
\hline TNM_M stage & & & & & $<0.001$ & & & \\
\hline No & 161 & 97.5 & 88.64 & 85.44 & & 1 & & \\
\hline Yes & 14 & 53.85 & 30.77 & - & & 5.24 & (1.876 14.649) & 0.002 \\
\hline
\end{tabular}


Table 5 Summary of different phenotypes between Lynch syndrome (LS) and familial colorectal cancer type X (FCCTX) in the literature

\begin{tabular}{|c|c|c|c|c|}
\hline & Age at diagnosis of CRC & Tumor location & Rate of meta-chronous CRC & $\begin{array}{l}\text { Rate of extra-colonic } 2^{\text {nd }} \\
\text { tumor }\end{array}$ \\
\hline & LS vs. FCCTX & LS vs. FCCTX & LS vs. FCCTX & LS vs. FCCTX \\
\hline \multirow[t]{4}{*}{ Valle [13] } & $\begin{array}{l}\text { Mean } \\
41 \text { vs. } 53 \text { years }\end{array}$ & Right colon & $26.3 \%$ vs. $7.7 \%$ & No data \\
\hline & $p<0.001$ & $70.6 \%$ vs. $20.8 \%$ & NS & \\
\hline & & Rectum & & \\
\hline & & $11.8 \%$ vs. $41.7 \%$ & & \\
\hline \multirow[t]{3}{*}{ Mueller-Koch [14] } & $\begin{array}{l}\text { Median } \\
41 \text { vs. } 55 \text { years }\end{array}$ & Right colon & $11.3 \%$ vs. $1.4 \%$ & $16 \%$ vs. $1.4 \%$ \\
\hline & $p<0.001$ & $68 \%$ vs. $14 \%$ & $p=0.017$ & $p<0.001$ \\
\hline & & $p<0.010$ & & \\
\hline \multirow[t]{3}{*}{ Xavier L [15] } & 64.8 vs. 67.8 years & Right colon & No data & $5.1 \%$ vs. $3.3 \%$ \\
\hline & $p=0.603$ & $44.4 \%$ vs. $13.3 \%$ & & NS \\
\hline & & $p=0.15$ & & \\
\hline \multirow[t]{4}{*}{ Shiovitz [6] } & $\begin{array}{l}\text { Mean } \\
53.3 \text { vs. } 50.5 \text { years }\end{array}$ & Right colon & No data & No data \\
\hline & & $61 \%$ vs. $31 \%$ & & \\
\hline & & Rectum & & \\
\hline & & $15 \%$ vs. $34 \%$ & & \\
\hline \multirow[t]{2}{*}{ Yamaguchi [16] } & $\begin{array}{l}\text { Median } \\
48 \text { vs. } 45 \text { years }\end{array}$ & Right colon & No data & $37.6 \%$ vs. $4 \%$ \\
\hline & $p=0.39$ & $56 \%$ vs. $62 \%$ & & $p=0.001$ \\
\hline \multirow[t]{5}{*}{ This study } & $\begin{array}{l}\text { Mean } \\
54.3 \text { vs. } 48.6 \text { years }\end{array}$ & Right colon & $8.3 \%$ vs. $1.8 \%$ & $16.7 \%$ vs. $1.8 \%$ \\
\hline & $p=0.007$ & $62 \%$ vs. $27 \%$ & $p=0.177$ & $p=0.005$ \\
\hline & & Rectum & & \\
\hline & & $12 \%$ vs. $42 \%$ & & \\
\hline & & $p<0.001$ & & \\
\hline
\end{tabular}

literature [6, 13-16], including age at time of CRC diagnosis, tumor location, rate of metachronous CRC, and rate of extra-colonic secondary tumors. As shown in Table 1, the age at time of CRC diagnosis was 6.3 years older for pMMR. There was a right colon predominance (61.7\% vs. $27.3 \%)$ for dMMR patients compared to a rectal tumor predominance $(41.8 \%$ vs. $11.7 \%)$ for pMMR patients. Furthermore, significantly higher frequencies of secondary-site primary tumors $(16.7 \%$ vs. $1.8 \%)$ and metachronous CRC (20.57 person-year vs. 6.18 personyear) were found in dMMR patients compared to pMMR patients. Moreover, we found significantly more N0 tumors in dMMR (70.8\%) compared with pMMR (50.9\%) $(p=0.049)$, as shown in Table 1.

In addition to noting different phenotypes between $\mathrm{dMMR}$ and $\mathrm{pMMR}$ subtype patients, this retrospective study determined that extended colectomy was performed more often for dMMR than pMMR patients ( $35.8 \%$ vs. $14.6 \%, p=0.004)$. Most studies recommend extended resection, such as subtotal or total colectomy rather than segmental resection or hemicolectomy, for the surgical treatment of dMMR or LS patients because of the high risk of metachronous CRC [14, 17-19]. However, no prospective or randomized study has demonstrated that extended resection confers a survival benefit compared with segmental resection for HNPCC patients. Furthermore, little is known about the ideal operation type may be tailored according to MMR status. In this study, we determined that the risk of metachronous colorectal cancer in pMMR subtype was significantly lower than that of dMMR subtype and comparable to that of sporadic CRC. Furthermore, in pMMR subtype patients, the tumor was more frequently located in the rectum, and extended colectomy, which was only performed in $14.6 \%$ of these patients, was not the preferred surgical treatment. However, segmental colectomy itself for pMMR patients did not significantly affect surgical outcomes and was not an independent 
factor for OS and DFS. Clinically, these two disease subtypes are both classified as HNPCC; the inherent difficulty lies in distinguishing the two because preoperative genetic testing such as microsatellite instability or dMMR status are not always available in daily clinical practice and may affect surgical decision making. However, surgeons have some clues that suggest pMMR subtype patients, such as older age (average age 54.3 years in this study), less right colon involvement $(27.3 \%$ in this study), and a higher rate of rectal involved ( $41.8 \%$ in this study) $[13,15]$. Thus, extended colectomy might be recommended for HNPCC patients without rectal tumor involvement and age younger than 50 years because of the higher rate of dMMR subtype with these features. In contrast, segmental resection might be recommended for HNPCC patients who present with rectal cancer and older age due to the high rate of pMMR with these features.

However, for all HNPCC patients, post-operation MMR status should be routinely checked. Post-operative colonoscopy and extra-colonic surveillance were thus individualized based on MMR data [17-19]. Postoperation frequent colonoscopy surveillance of dMMR subtype patients who undergo segmental or hemicolectomy is recommended because the risk of metachronous CRC becomes an important issue, as shown in this study (6.18 for pMMR patients and 20.57 person-years for dMMR patients, $p<0.001$ ). In this study, pMMR patients had a low rate of metachronous colorectal cancer, and $85 \%$ of these cases underwent segmental colectomy; this highlights the idea that as respect to pMMR patients might benefit from a follow-up program similar to that of sporadic CRC, because of the low incidence of secondary-site tumors. In addition, because of the low rate of secondary-site cancer in pMMR, the postoperative surveillance of these patients might target the CRC only, with a longer interval (such as $3-5$ years) [16, 18]. However, for dMMR patients, postoperative surveillance of secondary-site cancers $(15.0 \%$ vs. $5.3 \%)$ should be emphasized. Clinically, routine determination of postoperative tumor MMR status is strongly recommended to tailor surveillance programs and improve outcomes.

\section{Limitations}

This analysis benefits from the use of a cohort of patients with standardized computerized data collection, providing the opportunity to compare dMMR and pMMR subtypes for detailed analysis of clinicopathologic variables. However, the major limitation of this study is its retrospective nature. This study did not involve universal screening of mismatch repair proteins using immunohistochemical staining. Instead, screening was performed for cases whose family history fulfilled the A-II criteria. Therefore, few cases were missed in this cohort.

\section{Conclusion}

In addition to several distinct clinicopathological features existing between $\mathrm{dMMR}$ and pMMR subtypes patient, we found more N0 cases, more cases of extended colectomy, and significantly better DFS and OS for dMMR patients compared with pMMR patients. Postoperative tumor MMR status that is highly recommended routinely performed to tailor surveillance programs because of the significantly different risk of metachronous $\mathrm{CRC}$ and secondary-site tumors.

\section{Abbreviations}

CRC: Colorectal cancer; HNPCC: Hereditary non-polyposis colorectal cancer; pMMR: Proficient mismatch repair gene expression; dMMR: Deficient mismatch repair gene expression; DFS: Disease-free survival; OS: Overall survival; LS: Lynch syndrome; FCCTX: Familial colorectal cancer type $X$

\section{Acknowledgements}

The present study was supported by grants (to Jy-Ming Chiang) from the Chang Gung Research Foundation (CMRPG3D0421 and CMRPG3D0422). The authors thank and acknowledge the support of the Maintenance Project of the Center for Big Data Analytics and Statistics (Grant CLRPG3D0044) at

Chang Gung Memorial Hospital for statistical consultation and data analysis.

\begin{abstract}
Authors' contributions
JC made the concept and design of this study. Collection and assembly of data was done by $\mathrm{TC}$, and then the data analysis and interpretation was done by TC, CS, and JC. CS and JC wrote and edited the manuscript. HH, JY, and JC provided patients for this study. All authors read and approved the final manuscript.
\end{abstract}

Funding

This study was not funded by any outside source.

\section{Availability of data and materials}

The detailed patients' databases generated and analyzed during this study are not publicly available due to appropriate protection of patients' personal information but are available from the corresponding author on reasonable request.

Ethics approval and consent to participate

The study protocol was approved by the institutional review board of Taoyuan branch of Chang Gung Memorial Hospital as IRB102-2284B. Due to the retrospective design of the study, the local ethic committee confirmed that informed consent was not necessary from participants.

Consent for publication

Not applicable.

Competing interests

The authors declare that they have no competing interests.

\section{Author details}

${ }^{1}$ Division of Colon and Rectal Surgery, Department of Surgery, Chang Gung Memorial Hospital, Lin-Kou Medical Center, Tao-Yuan, Taiwan. ${ }^{2}$ College of Medicine, Chang Gung University, No. 5, Fu-Hsing Rd. Kuei-Shan, Tao-Yuan 333, Taiwan. ${ }^{3}$ Chang Gung University, College of Medicine, Tao-Yuan, Taiwan. ${ }^{4}$ Department of Pathology, Chang Gung Memorial Hospital, Lin-Kou Medical Center, Tao-Yuan, Taiwan. 
Received: 6 April 2020 Accepted: 30 July 2020

Published online: 07 August 2020

\section{References}

1. Lindor NM. Familial colorectal cancer type $X$ : the other half of hereditary nonpolyposis colon cancer syndrome. Surg Oncol Clin N Am. 2009;18(4):637-45.

2. Parry S, Win AK, Parry B, Macrae FA, Gurrin LC, Church JM, et al. Metachronous colorectal cancer risk for mismatch repair gene mutation carriers: the advantage of more extensive colon surgery. Gut. 2011;60(7):950-7.

3. Smyrk TC, Watson P, Kaul K, Lynch HT. Tumor-infiltrating lymphocytes are a marker for microsatellite instability in colorectal carcinoma. Cancer. 2001; 91(12):2417-22.

4. Lynch HT, Smyrk T, Lynch JF. Overview of natural history, pathology, molecular genetics and management of HNPCC (Lynch syndrome). Int J Cancer. 1996;69(1):38-43.

5. Chang SC, Lin PC, Yang SH, Wang HS, Liang WY, Lin JK. Taiwan hospitalbased detection of Lynch syndrome distinguishes 2 types of microsatellite instabilities in colorectal cancers. Surgery. 2010;147(5):720-8.

6. Shiovitz S, Copeland WK, Passarelli MN, Burnett-Hartman AN, Grady WM, Potter JD, et al. Characterisation of familial colorectal cancer type $X$, Lynch syndrome, and non-familial colorectal cancer. Br J Cancer. 2014;111(3):598-602.

7. Burke W, Petersen G, Lynch P, Botkin J, Daly M, Garber J, et al. Recommendations for follow-up care of individuals with an inherited predisposition to cancer. I. Hereditary nonpolyposis colon cancer. Cancer genetics studies consortium. JAMA. 1997;277(11):915-9.

8. Giardiello FM, Allen Jl, Axilbund JE, Boland CR, Burke CA, Burt RW, et al. Guidelines on genetic evaluation and management of Lynch syndrome: a consensus statement by the US multi-society task force on colorectal cancer. Am J Gastroenterol. 2014;109(8):1159-79.

9. Win AK, Parry S, Parry B, Kalady MF, Macrae FA, Ahnen DJ, et al. Risk of metachronous colon cancer following surgery for rectal cancer in mismatch repair gene mutation carriers. Ann Surg Oncol. 2013;20(6):1829-36.

10. de Vos tot Nederveen Cappel WH, Buskens E, van Duijvendijk P, Cats A, Menko $\mathrm{FH}$, Griffioen $\mathrm{G}$, et al. Decision analysis in the surgical treatment of colorectal cancer due to a mismatch repair gene defect. Gut. 2003;52(12):1752-5.

11. de Vos tot Nederveen Cappel WH, Nagengast FM, Griffioen G, Menko FH, Taal BG, Kleibeuker JH, et al. Surveillance for hereditary nonpolyposis colorectal cancer: a long-term study on 114 families. Dis Colon Rectum. 2002:45(12):1588-94.

12. Chen JR, Chiang JM, Changchien CR, Chen JS, Tang RP, Wang JY. Mismatch repair protein expression in Amsterdam II criteria-positive patients in Taiwan. Br J Surg. 2008;95(1):102-10.

13. Valle L, Perea J, Carbonell P, Fernandez V, Dotor AM, Benitez J, et al. Clinicopathologic and pedigree differences in Amsterdam I-positive hereditary nonpolyposis colorectal cancer families according to tumor microsatellite instability status. J Clin Oncol. 2007;25(7):781-6.

14. Mueller-Koch Y, Vogelsang H, Kopp R, Lohse P, Keller G, Aust D, et al. Hereditary non-polyposis colorectal cancer: clinical and molecular evidence for a new entity of hereditary colorectal cancer. Gut. 2005;54(12):1733-40.

15. Llor X, Pons E, Xicola RM, Castells A, Alenda C, Pinol V, et al. Differential features of colorectal cancers fulfilling Amsterdam criteria without involvement of the mutator pathway. Clin Cancer Res. 2005;11(20):7304-10.

16. Yamaguchi T, Furukawa Y, Nakamura Y, Matsubara N, Ishikawa H, Arai M, et al. Comparison of clinical features between suspected familial colorectal cancer type $X$ and Lynch syndrome in Japanese patients with colorectal cancer: a cross-sectional study conducted by the Japanese Society for Cancer of the colon and Rectum. Jpn J Clin Oncol. 2015:45(2):153-9.

17. Rodriguez-Bigas MA, Moeslein G. Surgical treatment of hereditary nonpolyposis colorectal cancer (HNPCC, Lynch syndrome). Familial Cancer 2013;12(2):295-300.

18. Syngal S, Brand RE, Church JM, Giardiello FM, Hampel HL, Burt RW, et al. ACG clinical guideline: genetic testing and management of hereditary gastrointestinal cancer syndromes. Am J Gastroenterol. 2015;110(2):223-62 quiz 63.

19. Haanstra JF, de Vos Tot Nederveen Cappel WH, Gopie JP, Vecht J, Vanhoutvin SA, Cats A, et al. Quality of life after surgery for colon cancer in patients with Lynch syndrome: partial versus subtotal colectomy. Dis Colon Rectum. 2012;55(6):653-9.

\section{Publisher's Note}

Springer Nature remains neutral with regard to jurisdictional claims in published maps and institutional affiliations.

Ready to submit your research? Choose BMC and benefit from:

- fast, convenient online submission

- thorough peer review by experienced researchers in your field

- rapid publication on acceptance

- support for research data, including large and complex data types

- gold Open Access which fosters wider collaboration and increased citations

- maximum visibility for your research: over $100 \mathrm{M}$ website views per year

At $\mathrm{BMC}$, research is always in progress.

Learn more biomedcentral.com/submissions 